\title{
Mission Diversity and Reputation in Higher Education
}

Frans van Vught

Center for Higher Education Policy Studies (CHEPS), University of Twente, Postbus 217, Enschede 75000, The Netherlands.

E-mail: f.a.vanvught@utwente.nl

In this contribution both the literature and the present-day policies regarding diversity in higher education systems will be discussed. The first part presents an overview of the theoretical and empirical studies on differentiation and diversity. Based on this, a conceptual framework is presented, which intends to explain the processes of differentiation and dedifferentiation in higher education systems. Two crucial variables are identified, and both have a crucial impact on the behaviour of higher education institutions: the level of uniformity in the environment of higher education institutions and the level of influence of academic norms and values in these institutions. The second part of this contribution focuses on current higher education policies. Hoping to create better and stronger contributions by higher education institutions to the 'knowledge society', many governments nowadays develop policies of less state control and more autonomy. It will be argued that these policies do not automatically lead to more diversity in higher education systems. The reason for this is simply that markets work imperfectly in higher education systems and that the behaviour of higher education institutions is triggered by competition for reputation, a process producing several unintended consequences. In this latter context the recent rankings and typologies in higher education are also discussed.

Higher Education Policy (2008) 21, 151-174. doi:10.1057/hep.2008.5

Keywords: diversity; differentiation; autonomy; market; reputation race

\section{Introduction}

This contribution addresses the concepts of diversity and differentiation in higher education systems. I intend to explore the literature regarding these concepts and to address a number of related higher education policy issues. I will also offer a conceptual framework that seeks to explain why processes of differentiation and dedifferentiation take place in systems of higher education.

Differentiation will be defined as a process in which new entities emerge in a system (in our case: a system of higher education). This definition is partly in line with Smelser (1959), who describes differentiation as a process whereby a social unit changes into two or more other units. According to 
Smelser, the 'new social units are structurally distinct from each other, but taken together they are functionally equivalent to the original unit' (Smelser, 1959, 2). However, unlike Smelser, I would like to include the emergence of completely new entities in the definition. Whereas Smelser limits his definition to the splitting up of existing units into new ones, I, like Rhoades, accept the coming into existence of completely new units as part of the definition (Rhoades, 1983, 285).

Differentiation as a concept should be distinguished from the concept of diversity. Diversity is a term indicating the variety of entities within a system. While differentiation denotes a dynamic process, diversity refers to a static situation. Differentiation is the process in which new entities in a system emerge; diversity refers to the variety of the entities at a specific point in time (Huisman, 1995, 51). The framework to be presented will be directed to differentiation and diversity of higher education systems. This implies that the focus will be at the level of higher education systems rather than of higher education institutions or of sets of programmes (of teaching and research) organized by these institutions. In terms of Birnbaum's (1983) typology of forms of diversity, the focus is on external diversity (a concept that refers to differences between higher education institutions), rather than on internal diversity (differences within higher education institutions).

When discussing external diversity and processes of system differentiation, I will analyse the behaviour of the various 'actors' in the system. These actors to a large extent are the higher education organizations that are part of a higher education system. I will interpret these organizations as 'corporate actors' (Coleman, 1990, 531), and will assume that the explanation of social phenomena like differentiation and diversity is possible by means of analysing the behaviour and/or opinions of these corporate actors who need not necessarily be natural persons (although the activities of corporate actors are of course carried out by people).

In the higher education literature several forms of diversity are mentioned. In a survey of the literature, Birnbaum (1983) identifies seven categories that are largely related to external diversity (Huisman, 1995):

- systemic diversity refers to differences in institutional type, size and control found within a higher education system;

- structural diversity refers to institutional differences resulting from historical and legal foundations, or differences in the internal division of authority among institutions;

- programmatic diversity relates to the degree level, degree area, comprehensiveness, mission and emphasis of programmes and services provided by institutions; 
- procedural diversity describes differences in the ways that teaching, research and/or services are provided by institutions;

- reputational diversity communicates the perceived differences in institutions based on status and prestige;

- constituential diversity alludes to differences in students served and other constituents in the institutions (faculty, administration);

- values and climate diversity is associated with differences in social environment and culture.

For our purposes, the distinction between external and internal diversity is the crucial one. We will focus on the differences between institutions rather than on differences within institutions.

\section{Classical and Recent Perspectives}

Diversity and differentiation have been studied in-depth in the past centuries. Crucial studies that come to mind include the seminal works of Darwin (Origin of Species, 1859), Durkheim (The Division of Labor in Society, 1893) and, more recently, Parsons (Societies: Evolutionary and comparative perspectives, 1966) and Merton (Social Theory and Social Structure, 1968).

The explanatory framework to be presented here draws heavily on three contemporary theoretical perspectives from organizational theory: the population ecology perspective, the resource dependency perspective and the institutional isomorphism perspective. Although these three perspectives have much in common, there are also some specific differences. As an introduction, let me briefly characterize each of the three perspectives.

The population ecology approach is based on the Darwinian evolutionary point of view. According to Hannan and Freeman, two of the most important authors in this field, the population ecology approach concentrates 'on the sources of variability and homogeneity of organisational forms... In doing so, it pays considerable attention to population dynamics, especially the processes of competition among diverse organizations for limited resources such as membership, capital and legitimacy' (1989, 13).

The resource dependency perspective stresses the mutual processes of interaction between organizations and their environments. According to this approach, organizations on the one hand are dependent on their environments (which primarily consist of other organizations) but on the other these organizations are also able to influence their environments. 'Rather than taking the environment as a given to which the organization then adapts, it is considerably more realistic to consider the environment as an outcome of a process that involves both adaptation to the environment and attempts to change that environment' (Pfeffer and Salancik, 1978, 222). 
The institutional isomorphism approach stresses that in order to survive, organizations have to adapt to the existence of and pressures by other organizations in their environment. These adaptation processes tend to lead to homogenization, as organizations react more or less similarly to uniform environmental conditions. Isomorphism is a constraining process that forces organizations to resemble other organizations that face the same set of environmental conditions (DiMaggio and Powell, 1983).

Further on I will use the theoretical notions of these three perspectives to develop a conceptual framework that intends to explain the processes of differentiation and dedifferentiation in higher education systems. Before doing so, let us first focus on the various arguments in favour of diversity and differentiation in higher education systems, and let us address the most relevant studies on these concepts in the literature.

\section{Arguments in Favour of Diversity}

Diversity has been identified in the higher education literature as one of the major factors associated with the positive performance of higher education systems. Birnbaum (1983) presents an overview of the various arguments found in the literature in favour of external diversity (which I have adapted somewhat). Many of these arguments appear to be highly relevant in the context of higher education policy making.

First, it is often argued that increase in diversity of a higher education system is an important strategy to meet student needs. A more diversified system is assumed to be better able to offer access to higher education to students with different educational backgrounds and with a variety of histories of academic achievements. The argument is that in a diversified system, in which the performance of higher education institutions varies, each student is offered an opportunity to work and compete with students of similar background. Each student has the opportunity to find an educational environment in which chances for success are realistic.

A second and related argument is that diversity provides for social mobility. By offering different modes of entry into higher education and by providing multiple forms of transfer, a diversified system stimulates upward mobility as well as honourable downward mobility. A diversified system allows for corrections of errors of choice; it provides extra opportunities for success; it rectifies poor motivation; and it broadens educational horizons.

Third, diversity is supposed to meet the needs of the labour market. The point of view here is that in modern society an increasing variety of specializations on the labour market is necessary to allow further economic and social development. A homogeneous higher education system is thought to be less able to respond to the diverse needs of the labour market than in diversified system. 
A fourth argument is that diversity serves the political needs of interest groups. The idea is that a diverse system ensures the needs of different groups in society to have their own identity and their own political legitimation. In less diversified higher education systems the needs of specific groups may remain unaddressed, which may cause internal debates in a higher education system and various kinds of disruptions.

A fifth, and well-known argument is that diversity permits the crucial combination of elite and mass higher education. Generally speaking, mass systems tend to be more diversified than elite systems, as mass systems absorb a more heterogeneous clientele and attempt to respond to a wider range of demands from the labour market. In his famous analysis of mass and elite systems, Trow (1979) has indicated that the survival of elite higher education depends on the existence of a comprehensive system of non-elite institutions. Essentially, Trow argues that only if a majority of the students are offered the knowledge and skills that are relevant to find a position in the labour market, will a few elite institutions be able to survive.

A sixth reason why diversity is an important objective for higher education systems is that diversity is assumed to increase the level of effectiveness of higher education institutions. This argument is made for instance by the Carnegie Commission (1973) that has suggested that institutional specialization allows higher education institutions to focus their attention and energy, which helps them in producing higher levels of effectiveness.

Finally, diversity is assumed to offer opportunities for experimenting with innovation. In diversified higher education systems, institutions have the option to assess the viability of innovations created by other institutions, without necessarily having to implement these innovations themselves. Diversity offers the possibility to explore the effects of innovative behaviour without the need to implement the innovation for all institutions at the same time. Diversity permits low-risk experimentation.

These various arguments in favour of external diversity show that diversity is usually assumed to be a worthwhile objective for higher education systems. Diversified higher education systems are supposed to produce higher levels of client orientation (both regarding the needs of students and of the labour market), social mobility, effectiveness, flexibility, innovativeness and stability. More diversified systems, generally speaking, are thought to be 'better' than less diversified systems. And many governments have designed and implemented policies to increase the level of diversity of higher education systems.

Unfortunately, it is not always clear how an increase of a higher education system's diversity should be realized. The many governmental policies that have been developed and implemented do not always lead to the desired results. It appears that, although these concepts have a long tradition in the social sciences, diversity and differentiation are still only partly understood. 


\section{Studies on Differentiation and Diversity in Higher Education}

The concepts of diversity and differentiation have been widely discussed in the higher education literature. In this section, I present a brief categorization of the most influential studies (for a more elaborate overview see Huisman, 1995).

It appears that many studies on diversity and differentiation in higher education can be distinguished according to the question whether differentiation or dedifferentiation processes are assumed to take place in higher education systems. On the one hand, there are studies that claim that higher education systems show an immanent drive towards differentiation and increasing levels of diversity. On the other hand, there are studies that argue that higher education systems are characterized by dedifferentiation and decreasing levels of diversity.

Examples of the category of studies claiming an immanent drive towards increasing levels of diversity are Parsons and Platt (1973) and Clark (1978).

In their well-known study on the US higher education system, Parsons and Platt discuss, in addition to several other themes, the processes of differentiation within higher education systems. Their main argument appears to be that processes of differentiation occur when new functions emerge in a system. An example is the development of the graduate schools, which have come to be differentiated from undergraduate colleges. However, differentiation apparently does not necessarily imply the coming into existence of a new type of organization, as the authors also argue that new functions can be integrated in existing organizations.

Clark's argument regarding diversity and differentiation is based on his conviction that the growing complexity of bodies of knowledge brings along an ever-increasing fragmentation within and among higher education organizations. According to Clark (1983), the increasing complexity of higher education systems (and of the functions this system must fulfil) is an outcome of three related forces: the increasing variety of the student population, the growth of the labour market for academic graduates and the emergence and growth of new disciplines. The effects are ongoing differentiation processes and increasing levels of diversity. Emphasizing that differentiation often is in the interest of groups and individuals, Clark underlines the immanent drive towards differentiation in higher education: 'Once created and made valuable to a group, often to an alliance of groups, academic forms persist. Out of successive historical periods come additional forms, with birth rate greatly exceeding death rate. Differentiation is then an accumulation of historical deposits' (Clark, 1983, 221).

Next to the studies that claim that higher education systems show a more or less permanent drive towards differentiation stand the studies that argue that dedifferentiation is the name of the higher education game. 
Frans van Vught

Examples of this category of studies are Riesman (1956), Birnbaum (1983) and Rhoades (1990).

In his classical study Constraint and Variety in American Education (1956), Riesman compares the US higher education system with a kind of reptilian procession during which certain higher education institutions will move to the positions where other institutions were before. According to Riesman, this procession is the result of the typical behaviour of higher education institutions, which basically consists of lower status institutions trying to gain status by imitating higher status institutions (especially the prestigious research universities). This imitating behaviour, also indicated as 'academic drift' (Neave, 1979), creates a tendency towards uniformity and decreasing levels of diversity.

Birnbaum (1983) not only presents an elaborate classification on forms of diversity (in which seven forms of diversity are identified), he also tries to empirically assess the changes in external diversity in the US higher education system between 1960 and 1980. His findings show that during this period the number of institutional types had not increased and thus that differentiation had not occurred. Birnbaum hypothesizes that especially centralized state-level planning and the application of rigid criteria for the approval of new institutions and programmes hamper differentiation processes. Governmental policies, says Birnbaum, may be a major factor in producing processes of dedifferentiation and decreasing levels of diversity.

Rhoades' (1990) argument is that processes of dedifferentiation are the result of political competition between academic professionals and (external) lay groups, and governmental policies that structure these processes of competition. Rhoades indicates that as an effect of governmental policies and administrative systems in higher education, the power of the academic professionals is often quite large. The power balance between academics and lay groups to a large extent determines whether differentiation actually occurs. Comparing the developments in the higher education systems of the UK, France, Sweden and the US, Rhoades concludes that academics have been successful in defending their own norms and values and hence have prevented differentiation processes from taking place.

The various studies just presented show that external diversity and differentiation have been regularly addressed by higher education scholars. However, these studies also show that rather different points of view appear to exist regarding the direction of differentiation or dedifferentiation processes in higher education systems. Are these systems showing an immanent drive towards differentiation because of the emergence of new functions (Parsons and Platt) or because of the growing complexities of the bodies of knowledge and the variety of the student body and the labour market (Clark)? Or are systems of higher education to be characterized by immanent processes of 
dedifferentiation because of the imitating behaviour by lower status institutions (Riesman), centralized and uniform governmental policies (Birnbaum) or academic conservatism (Rhoades)?

In my own approach, I will combine some of these factors into a conceptual framework that seeks to explain external diversity in higher education systems.

\section{A Theoretical Framework for Explaining Differentiation and Diversity in Higher Education Systems}

In this paragraph, I will try to sketch the framework for a theory of differentiation and diversity in higher education systems. My point of departure will be the well-known 'open systems approach' in the social sciences. Using this approach, I interpret higher education as a system consisting of individual higher education organizations (being the components - or subsystems - of the higher education system) embedded in an environment that includes the social, political and economic conditions within which the higher education organizations need to operate. Being an open system, the higher education system is open to its environment, which implies that its components are both able to receive inputs (in the form of students, faculty, finances and other resources) and to deliver outputs (in the form of graduates, research, results and advice). This leads me to a first assumption for my theoretical framework:

Assumption 1: Organizations for higher education receive inputs from, and produce outputs for, their environments.

To the still rather general open systems approach, I add the three (mutually related) theoretical perspectives from organizational theory that were briefly introduced earlier: the population ecology perspective, the resource dependency perspective and the institutional isomorphism perspective.

The population ecology perspective has been sketched by Morgan $(1986,66)$ in the following terms: 'Organisations, like organisms in nature, depend for survival on their ability to acquire an adequate supply of resources necessary to sustain existence. In this effort they have to face competition with other organizations, and since there is usually a resource scarcity, only the fittest survive. The nature, number and distribution of organizations at any given time is dependent on resource availability and on competition within and between different species of organizations'.

In the population ecology model, the environment is the critical factor. The environment determines which organizations succeed and which fail. The environment acts as the critical selector. This point of view is clearly based on the Darwinian evolutionary perspective of variation, selection and retention. 
Variation may take place by means of various sources (planning, but also error, chance, luck and conflict; see Aldrich, 1979, 28). Selection is the process by which the organizations that fit particular environmental conditions are positively selected. Retention is the process in which the selected variations are preserved (Aldrich, 1979, 28-31).

There are a few theoretical notions of the population ecology perspective that need our special attention. One is that the theoretical model is directed to understanding the dynamics of whole populations of organizations, rather than of individual organizations. In the work by Aldrich, Hannan and Freeman, and others, the population ecology perspective refers to the aggregate study of organizations, that is, the organization that fall within a certain 'population'. The emphasis of the theoretical model is on the rise and decline of different species of organizations, as well as on their shared characteristics.

This focus on populations of organizations is less relevant for our purposes. Given the wish to develop a theoretical framework for the explanation of differentiation and diversity in higher education systems, a focus on the rise and decline of species of organizations (and hence on a very large time frame) appears to be less fruitful. Rather, the theoretical framework should address the ways by which processes of differentiation take place in higher education systems, as well as the resulting levels of diversity.

Another crucial insight of the population ecology model (as already indicated) is the idea that it is the ability of organizations to acquire relevant environmental resources (i.e., to obtain a resource niche) that is most important for success and survival. Organizations need an input of resources from their environment to be able to sustain existence. When resources are scarce, those organizations that are better able to secure a more or less permanent input have a better chance of survival.

Related to this notion is the important emphasis on competition. In the population ecologists' view, the process of competition for scarce resources will show which organizations are able to outperform their competitors and hence have a better chance to find a successful resource niche.

From the population ecology perspective I take two further assumptions for a theory of differentiation and diversity in higher education systems:

Assumption 2: In order to survive, higher education organizations need to secure a continuous and sufficient supply of resources from their environments.

Assumption 3: When scarcity of resources exists, higher education organizations compete with each other to secure a continuous and sufficient supply of resources.

This brings us to the important concept of structural isomorphism. In the population ecology perspective, the competition between organizations 
produces a certain correspondence between, on the one, the environmental conditions (resources and constraints) and, on the other hand, the structural characteristics of organizations. According to Hannan and Freeman, the diversity of organizational forms is proportional to the diversity of resources and constraints in their environments (Hannan and Freeman, 1989, 62). These authors also claim that the competition for scare resources causes competing organizations to become similar. The conditions of competition lead to similar organizational responses and, moreover, to the elimination of the (dissimilar) weaker organizations. The result is an increase of homogeneity (structural isomorphism) (Hannan and Freeman, 1977, 939).

However, the population ecology perspective has been criticized for exactly this notion of decreasing diversity under conditions of competition for scarce resources. Hawley (1986), for instance, contests Hannan and Freeman's assumption that competition for scarce resources causes structural isomorphism: 'As a type of relation, competition is readily observable; as a producer of particular outcomes it is obscure. At most it helps account for the elimination of some contestants from a share of the limited resource' (Hawley, 1986, 127). Apparently the relationships between environmental conditions, competition and diversity need further exploration.

At this point I turn to the two other (and related) perspectives from organizational theory: the resource dependency perspective and the institutional isomorphism perspective.

Although closely related to the population ecology perspective, the resource dependency perspective also shows an important distinction. While the population ecology model tends to emphasize the unidirectional organizational dependency on environmental conditions, the resource dependency model underlines the idea of mutual influencing. The environment certainly is perceived as having a major impact on organizational behaviour but, at the same time, organizations are also assumed to have certain effects on their environment. Pfeffer and Salancik $(1978,222)$ state this point of view as follows: 'The view that organisations are constrained by their political, legal and social environment is only partially correct ... organisations are not only constrained by their environments but ... in fact, law, legitimacy and political outcomes somewhat reflect the actions taken by organisations to modify their environments for their interests in survival, growth and certainty'.

I like to follow this line of argument and I assume that organizations (also in higher education) are affected by their environmental conditions, but are also able to affect these conditions.

Assumption 4: Higher education organizations both influence and are influenced by their environmental conditions. 
Returning to the relationships between environmental conditions, competition and diversity, we are now not only able to formulate the expectation that competition for scarce resources forces organizations to more or less similar responses, but also that, when confronted with scarcity of resources, organizations may want to try to influence their environmental conditions in order to secure better conditions. To the notion of the population ecology perspective of structural isomorphism as a result of competition for scarce resources, we now add the insight from the resource dependency perspective that, confronted with scarcity, organizations can act to influence their environment. The remaining question of course is how organizations tend to act when their supply of resources is threatened. To find an answer to this question, let us look at the perspective of institutional isomorphism.

The basic view of this perspective is that the survival and success of organizations depends upon taking account of other organizations in the environment. According to DiMaggio and Powell (1983), this leads to three forms of institutional isomorphism, all leading to an increasing similarity in organizational behaviour and producing a decrease of systems diversity. Coercive isomorphism results from the pressures applied by other organizations (in the environment) on which the organization is dependent (e.g., governmental policies and laws). Mimetic isomorphism stems from uncertainty caused by poorly understood technologies, ambiguous goals and the symbolic environment, which induces organizations to imitate the behaviour of perceived successful organizations. Normative isomorphism stems from professionalization. Professionalism leads to homogeneity both because formal professional training produces a certain similarity in professional background and because membership of professional networks further encourages such a similarity.

It may be clear from these three forms of institutional isomorphism that, according to DiMaggio and Powell, both certain environmental conditions (e.g., governmental policies) and specific organizational characteristics (e.g., the perceived uncertainty of the environment and the degree of professionalization of the organization) may produce dedifferentiation processes. The argument appears to be that, confronted with scarcity of resources, organizations may either be forced to react in such a way that dedifferentiation processes occur, or they may themselves show a behaviour that contributes to a decrease in the external diversity of the overall system.

Using the insights from the three perspectives of organizational theory we may, I argue, formulate some general relationships between, on the one hand, environmental conditions and (de)differentiation, and, on the other hand, organizational behaviour and (de)differentiation. Keeping the factors suggested in the higher education literature in mind, a first proposition could be that the level of uniformity/variety of the environment of the organization is 
related (by means of the organization's adaptive behaviour) to the level of diversity of the higher education system. This proposition follows the notion of the population ecology model of competition under conditions of scarce resources, it underscores the argument of coercive isomorphism and it accepts the idea that it is the organization itself that shows the relevant adaptive behaviour.

Proposition 1: The larger the uniformity of the environmental conditions of higher education organizations, the lower the level of diversity of the higher education system.

Relevant factors from the higher education literature that could be used to test this proposition are the level of uniformity of governmental policies (Birnbaum) and the level of variety in the student body and in the needs of the labour market (Clark).

A second proposition can be formulated when we focus on the general relationship between organizational behaviour and (de)differentiation. Again referring to some of the factors mentioned in the higher education literature (see above), the proposition could be that the level of influence of academic norms and values in a higher education organization is related (by means of either academic professionalism or imitating behaviour) to the level of diversity of the higher education system. Also this proposition follows the notion of competition under conditions of scarce resources, it emphasizes the arguments of mimetic and normative isomorphism and it accepts the ability of the organization to choose its own behaviour.

Proposition 2: The larger the influence of academic norms and values in a higher education organization, the lower the level of diversity of the higher education system.

Relevant factors from the higher education literature to test this proposition are the ability of academic professionals to define and defend the (academic) norms and values as relevant for higher education organizations (Rhoades) and the extent to which academic norms and values guide the imitating behaviour by lower status institutions (academic drift) (Riesman).

The two propositions offer a combination of structural isomorphism caused by competition (from the population ecology model) and institutional isomorphism caused by coercive, mimetic and normative pressures (from the institutional isomorphism model). In addition, the propositions show that the actual occurrence of processes of differentiation and dedifferentiation has to be explained by the combination of (external) environmental conditions and (internal) organizational characteristics. Either the tension between or the 
joining of these forces can offer a coherent explanation for processes of differentiation or dedifferentiation and thus for lower or higher levels of external diversity in a higher education system.

\section{Higher Education Research Outcomes}

Let us now return to the higher education literature and try to find some empirical indications that may be related to the conceptual framework. Are there outcomes of empirical higher education research that are relevant for testing our theoretical notions?

There appear to be remarkably few studies that produce empirical outcomes on diversity and differentiation in higher education. A few relevant studies can be mentioned. Huisman et al. (2007) recently undertook a cross-national and longitudinal analysis of 10 higher education systems. They found that, generally speaking, system size (the number of higher education institutions in a system) does not necessarily imply a high level of diversity. In addition, it appeared that governmental regulation may help to preserve a formally existing level of diversity in a higher education system, but that government initiated merger operations bring about more homogeneity rather than an increase of diversity. The explanation offered by the authors is in line with our conceptual framework. They suggest that legally mandated boundaries in higher education systems (as for instance in legally regulated binary systems) are preserving the existing level of diversity, but that governmental policies that offer more autonomy to higher education institutions encourage these institutions to emulate the most prestigious ones.

The already mentioned studies by both Birnbaum (1983) and Rhoades (1990) also appear to offer empirical support for the theoretical framework presented. Birnbaum found that during the period 1960-1980, the external diversity of the US higher education system had not increased although the system had grown enormously. 'It appears that the higher education system has used the vast increase in resources primarily to replicate existing forms (such as the community college) rather than to create new ones' (Birnbaum, 1983, 144). In a recent study, Morphew has repeated Birnbaum's study for the period 1972-2002. His findings reveal that, although the study period exhibited great change in the US higher education system, there is zero (or negative) growth in the general diversity of US higher education (Morphew, 2006).

Rhoades (1990) compared the developments in the higher education systems of the UK, France, Sweden and the USA between 1960 and 1980. His general finding appears to be that, although these systems show a certain amount of change, the processes of dedifferentiation were predominant. Rhoades expected that, because of a decrease in the financial resources for higher 
education during this period, the competition between the higher education institutions would increase, which would produce an increase in diversity. While discussing his empirical findings, he on the one hand suggests that several of the governments of the four countries have taken initiatives to introduce new types of institutions, but on the other hand he concludes that these governments (as well as accreditation boards) have contributed to dedifferentiation. In addition, Rhoades argues, it appears that in the four countries the influence of especially academic professionals has been substantial. Academics appear to be able to define and monopolize the nature of their professional activities, and, by doing so, preserve the existing status $q u o$. Academic professionals appear to be successful in resisting initiatives to change the system and in inhibiting processes of differentiation.

Several other empirical studies on differentiation in higher education systems appear to point in the same direction. In an analysis of differentiation processes in the Canadian higher education system, Skolnik (1986) comes to conclusions that are rather similar to the ones formulated by Birnbaum and Rhoades. According to Skolnik, the Canadian higher education system is faced with pressures towards homogenization because of both the restricting provincial steering approaches and the strong dominance of the values and norms of academic professionals.

In a study of the changes in the Dutch higher education system, Maassen and Potman (1990) analysed the university 'development plans'. Their objective was to find out whether the universities had been able to use their enlarged autonomy (the result of new governmental policy) to create more diversity in the system. Their conclusion is negative: ' $\ldots$ innovations all seem to go into the same direction of homogenization. As far as the development plans are concerned, the institutions have not succeeded in establishing meaningful and discriminating profiles. On the contrary, it seems likely that various homogenizing developments will emerge' (Maassen and Potman, 1990, 403). According to the authors, the combination of governmental regulations and the power of the academic professionals (especially in the quality control system) explain the trend towards decreasing diversity.

Meek (1991) has analysed the structural changes in the Australian higher education system. An increase of institutional autonomy, the demise of the binary system and a large-scale merger operation were assumed to allow for more diversity in the system. According to Meek, the strong academic values and norms, as well as the processes of academic drift tend to inhibit the increase of diversity. Dedifferentiation rather than differentiation appears to be the case in the Australian system.

The various empirical studies appear to underline the notions of the theoretical framework presented earlier. According to the authors of these studies, environmental pressures (especially governmental regulation) as well as 
the dominance of academic norms and values are the crucial factors that influence the processes of differentiation and dedifferentiation in higher education systems. In all cases, the empirical observations point in the direction of dedifferentiation and decreasing levels of diversity. The overall impression is that, in empirical reality, the combination of strict and uniform governmental policies and the predominance of academic norms and values leads to homogenization.

However, it should be kept in mind that the theoretical framework also suggests other possible outcomes. When the environmental conditions are varied and when the influence of academic norms and values in a higher education institution is limited, the level of systems diversity may be expected to increase. Also, according to the theoretical framework, the combinations of uniform environmental conditions and limited influence of academic norms and values on the one hand, and of varied environmental conditions and large influence of academic norms and values on the other, might be related to either increasing or decreasing levels of diversity.

In addition, it may be pointed out that the pressures from governmental regulation do not necessarily have to be seen as mechanisms for homogenization. As has been indicated by Huisman et al. and Rhoades, governmental policies may also play an important role in maintaining existing and formally regulated levels of diversity, if necessary, by containing academic conservatism and/or imitating behaviour by lower status institutions. From this point of view, the regulatory policy regarding the complex tripartite structure of the public sector higher education system of California appears to be interesting. Although tensions exist within this system, it appears that the California Master Plan has succeeded in preventing homogenization processes from occurring. A conscious legislative decision to maintain a certain level of diversity in the public system apparently has been able to restrain academic drift (Fox, 1993).

A recent and interesting approach to maintaining and even increasing the diversity of a higher education system is the process followed by the University Grants Committee (UGC) of Hong Kong. The UGC entered into an open discussion with each of the (eight) universities of the Hong Kong higher education system and stimulated them to formulate their specific missions and roles in the context of the broader system. Subsequently, these missions and roles were formalized in agreements between the individual institutions and the UGC. During this process, the UGC kept an eye on its objective to increase the diversity at the level of the system. Finally, after a few years, the UGC developed a 'Performance and Role-related Funding Scheme', in which it explored, together with the individual institutions, whether they had been able to remain within the parameters of their mission and role statements. The result was a clear increase of the diversity of the Hong Kong higher 
education system and even a growing enthusiasm with the institutions to stick to their roles.

\section{Higher Education System Diversity and the 'Knowledge Society'}

It is a familiar argument by now: the Western world has entered the phase of the 'knowledge society'; our future prosperity and welfare will to a large extent depend on our ability to create and apply knowledge; our economic growth is dependent upon the ways we are able to work with useful knowledge. Nation states and whole continents underline their ambitions to become global competitors in terms of the knowledge economy. The European Union has, for instance, indicated that it intends to become the world's most dynamic and competitive knowledge economy by the year 2010 .

The 'knowledge economy' is at the heart of many governmental policies these days. Governments design policies that intend to stimulate the creation and application of knowledge in economic activities; they try to stimulate 'academic entrepreneurialism', the use of IPR, the setting up of venture capital funds and the intensity of cooperation between universities and business and industry.

Given these ambitions, political leaders increasingly address higher education institutions. They craft higher education policies that intend to influence the behaviour of these institutions and of the faculty working within them. Generally speaking these policies regard the trade-off between autonomy and accountability; between less state control and more self-management on the one hand (van Vught, 1992) and more efficiency and especially responsiveness to societal needs on the other (Meek, 2003).

A crucial aspect of these policies regards the wish of governments to create higher levels of diversity in national higher education systems. More diversity is assumed to better serve the needs of the labour market, to offer more and better access to a larger student body and to allow institutional specialization by which the effectiveness of the overall higher education system increases. Particularly the latter argument is regularly presented in the context of developing the 'knowledge society'. In order to make them more responsive to societal needs, higher education institutions should be stimulated to develop their specific missions and profiles, jointly creating a diversified higher education system in which different types of institutions co-exist.

The policy argument that governments use is rather straightforward and goes as follows. Higher education institutions need to become more responsive to the needs of the knowledge society. They need to increase their capacity and willingness to become engaged in the production of useful knowledge. And they need to develop their own specialized missions and profiles. In order to 
stimulate these institutions to do so, the mechanism of market coordination can be used. Reinforcing the demand side of the market (by increasing consumer sovereignty) will increase the sensitiveness to consumers' wishes, the level of institutional specialization and the level of competition between universities. The result will be higher-quality outputs, a more diversified system and an increasing responsiveness to societal needs.

It seems to me that the validity of this policy argument can be questioned. First, the outputs of higher education institutions are usually heavily subsidized, both by public funding and by private gifts. Supply and demand do not set a market-clearing price for the outputs of higher education institutions (Geiger, 2004, 17). The subsidization processes also create market distortions, especially because of the uneven distribution of the public and private resources that are poured into higher education (Newman et al., 2004, 90). In higher education systems the price mechanism works imperfectly.

Secondly, the introduction of more consumer sovereignty in higher education systems does not necessarily trigger the behaviour of higher education institutions that governments are trying to accomplish. Given the specific nature of their 'products and services', higher education institutions often are able to use their autonomy to resist the pressures of the increase of consumer power.

There is simple explanation for this. The products and services that higher education institutions offer are 'experience goods' (Dill, 2003): the clients of universities are only able to judge the relevance and the quality of the outputs of higher education, when they are able to experience them. Students can only really judge the quality of a course when they take it; and research clients can only really judge the quality of a research project when they are offered the results. When confronted with the question to take a decision in favour of a certain product or service of an institution for higher education, clients (including potential students) are hampered with the well-known market failure of imperfect information. Higher education institutions, on their part, are enticed by these conditions to represent themselves in the best possible ways. They underline their self-acclaimed qualities hoping that by emphasizing these, they will be able to convince the clients of their attractiveness.

As a result of this, the consumer market works imperfectly in higher education (Massy, 2003, 42). In the words of Joseph Stiglitz: 'Recent advances in economic theory have shown that whenever information is imperfect and markets incomplete, ... then the invisible hand works imperfectly' (quoted in Friedman, 2002, 50). Increasing consumer sovereignty therefore does not automatically lead to an increase of responsiveness to societal needs by higher education institutions and to more diversity in a higher education system. Rather the behaviour of these institutions is triggered by the conditions of another market, that of competition for institutional reputation. 
Frans van Vught

Mission Diversity and Reputation in Higher Education

168

\section{The Higher Education 'Reputation Race'}

In his classic The Higher Education System, Clark explores three major types of markets that are relevant in higher education systems: consumer markets, 'where people normally exchange money for desired goods or services', labour markets, 'in which people offer their capabilities and energy for money' and institutional markets, 'where enterprises interact with one another, instead of with consumers or employees' (Clark, 1983, 162-165). It is the first market (consumer markets) that appears to be the object of many governmental policies that try to increase the coordinative capabilities of market forces in higher education. By increasing the capacity of the consumers of higher education outputs (students, clients) to choose among the various products of higher education institutions, these policies intend to strengthen the consumer market. However, exactly because of another higher education market mentioned by Clark, these policies are usually only marginally effective. Let me explain this.

The actions of universities and other higher education institutions appear to be particularly driven by the wish to maximize their (academic) prestige and to uphold their reputations (Garvin, 1980; Brewer et al., 2002). Universities seek to hire the best possible faculty (on the higher education labour market) and they try to recruit the most qualified students (on the higher education consumer market). They do so because they are 'intensely concerned with reputation and prestige' (Geiger, 2004, 15).

Given this drive, higher education institutions are first and foremost each other's competitors (on the institutional market). They compete among themselves for the best students, the best faculty, the largest research contracts, the highest endowments, etc. They compete for all the resources that may have an impact on their institutional reputation.

Geiger (2004) argues that this competition for reputation is played out in two principal arenas, one comprising faculty scholarship and the other reflecting the recruitment of students. In the first arena, universities try to recruit and employ the best scientists, that is, those scholars with the highest recognition and rewards, the highest citation impact scores and the largest numbers of publications. In order to be able to do so, they continuously feel the need to increase their staff expenditures, especially in research (since it is this context that scholars are attracted to), creating a continuous need for extra resources. The second arena regards the recruitment of students. Given their wish to increase their reputation, universities try to attract the most talented students. They use selection procedures to find them, but they also offer grants and other facilities in order to be able to recruit them, again leading to a permanent need for extra resources.

The concept of 'reputation in higher education' needs some further exploration. The reputation of a higher education institution can be defined 
as the image (of quality, influence, trustworthiness) it has in the eyes of others. Reputation is the subjective reflection of the various actions an institution undertake to create an external image. The reputation of an institution and its quality may be related, but they need not be identical. Higher education institutions try to influence their external images in many ways, and not only by maximizing their quality.

The dynamics of higher education are first and foremost a result of the competition for reputation. Higher education systems are characterized by a 'reputation race'. In this race, higher education institutions are constantly trying to create the best possible images of themselves as highly regarded universities. And this race is expensive. Higher education institutions will spend all the resources they can find to try to capture an attractive position in the race. In this sense, Bowen's famous law of higher education still holds: ' $\ldots$ in quest of excellence, prestige and influence... each institution raises all the money it can ... [and] spends all it raises' (Bowen, 1980, 20).

\section{Unintended Consequences}

As indicated before, in many countries across the world, a shift is taking place in public policy regarding higher education. Even in countries where state regulation used to be the dominant factor with respect to the dynamics of higher education systems, now new policies are emerging designed to create markets in higher education, to strengthen the ties with industry and to stimulate higher levels of external diversity.

Newman et al. (2004) see two main causes for this international development in public policy. One is the previously mentioned wish of political leaders to use the assumed positive forces of increased competition and consumer sovereignty to make higher education institutions more responsive to the needs of society, especially with respect to the knowledge economy. I argued before that this argument fails to appreciate the strength of another market in higher education, that of institutional reputation.

The other cause for the international shift of public policy towards markets, and an increase of competition, is the behaviour of universities themselves. When confronted with the temptations of more autonomy and self-management, university leaders are most willing also to accept the increased competition that is often used as an argument for even more autonomy: 'We need greater autonomy in order to compete' (Newman et al., 2004, 34).

However, the introduction through public policy of increased competition may lead to a number of unintended consequences in the dynamics of higher education systems that do not necessarily contribute to a better responsiveness to societal needs. 
First, the total cost of higher education appears to be growing immensely. The reputation race implies that universities are in constant need of more resources. They need these resources to recruit better staff, to offer more study grants, to upgrade their facilities, to improve their PR, etc. 'Universities press their pricing up to the limits that markets, regulators, and public opinion will allow. They justify their actions in terms of the rising cost of excellence and other factors beyond their control, but that is only part of the story. The impetus for price hikes stems from the university's own choices...' (Massy, $2003,39)$. It stems from its drive to engage in the academic reputation race.

The effect is an impressive increase of the spending levels of higher education institution. Geiger (2004), for instance, shows that the per student spending between 1980 and 2000 in the US rose by $62 \%$ at public universities and more than double at private institutions (Geiger, 2004, 32, 262). In the US, higher education has become far more expensive during recent decades. And although participation rates have grown and students have certainly benefited from these increases of spending levels, it may also be pointed out that, in particular, the private costs of higher education have gone up dramatically. In the US 'the costs of higher education borne by students nearly doubled in real terms from 1978 to $1996 \ldots$ The costs of going to college.... grew nearly twice as fast as the economy' (Geiger, 2004, 33). When public policies in other countries tend to follow the US example of increasing the competition in a system where reputation is the major driving force, similar cost explosions should be expected.

It should also be pointed out that the shift of the costs of higher education from public to private sources implies that the social returns of higher education are increasingly being overshadowed by the private benefits. In this sense, the introduction of consumer sovereignty and competition implies a 'privatization' of higher education. Students and graduates increasingly demand 'value for money' for their investments, and higher education institutions may be tempted to 'reduce the value of learning to simply the opportunity to earn more upon graduation' (Newman et al., 2004, 44).

A second consequence of the introduction of increased competition appears to be an increase of the wealth inequalities among institutions. In traditional continental European public policies with respect to higher education, institutions were assumed to be equal and (largely) similar. The new policies however emphasize the importance of differences between institutions. Universities are stimulated to compete and to develop specific roles and profiles, to relate to specific stakeholders and to respond to regional needs. This increase of competition leads to greater inequalities among institutions, because there is no 'level playing field'. The reputation race works out differently given different levels of resources; the higher these levels are, the more an institution will be able to climb the ladder of reputation. Higher 
education institutions can only hire the faculty whose salaries they can afford. But they can also only charge the tuition fees that are justified by the level of their reputation. The reputation race is fuelled by an insatiable need for funding. Richer institutions are more easily able to increase their reputation than poorer institutions. And this process is self-reinforcing: as the race goes on, the wealth inequalities and the differences in reputation tend to increase. The result is the establishment and strengthening of institutional hierarchies. Increased competition thus creates hierarchical differentiation in higher education systems.

Thirdly, the new public policies (and the creation of institutional hierarchies) are accompanied by a greater social stratification of students. Highly reputable institutions try to enrol high-ability students. In order to accomplish this, they apply high-tuition/high-aid strategies, trying to attract and select those students who are most talented and whose enrolments reflect on their prestige. The result is a social stratification based on merit. Higher education systems become more stratified by academic ability. Both students and institutions act in such a way that a meritocratic stratification is produced.

Even though student-aid policies are designed to create opportunities for the least advantaged, increased competition leads institutions to focus either on those students who have the financial resources themselves, or on those who have the highest abilities (and who can be offered grants). According to Newman et al. (2004), in the US the less-advantaged students have become the victims of this development. 'The price war that has broken out among institutions and even among states, grounded in the financial aid offered to attractive students, favours the already advantaged. They are also the ones knowledgeable enough about the system to seek out and attract competitive offers' (Newman et al., 2004, 87).

Cost explosions, institutional hierarchies and the social stratification of the student body are not necessarily the consequences that political actors have in mind when they design the public policies that should stimulate higher education institutions to become more responsive to societal needs. They also are not the consequences that are foreseen when higher levels of external diversity are stimulated. They are, however, possible effects of the introduction of an increase of competition in higher education systems. Because of the dynamics of the reputation race, these effects may very well occur. The more autonomy the higher education institutions acquire, the more they will intend to engage in this competition for reputation. Public policy makers in higher education should be aware of these dynamics and look for more effective ways to create the contexts that can stimulate the application of knowledge and the creation of more diversified higher education systems. 
Frans van Vught

Mission Diversity and Reputation in Higher Education

172

\section{Rankings and Typologies}

The recent popularity of world university rankings only appears to amplify the higher education reputation race. The annual Shanghai Jiao Tong University ranking (commenced in 2003) and the Times Higher Education Supplement ranking (commenced in 2004) provide extra stimuli for both policy makers and higher education institutions to try to conquer higher positions at the global ladders of institutional reputation. Because they largely tend to favour traditional academic performance, particularly in research, these ranking instruments lead to an increase of mimicking behaviour (imitating the highreputation institutions), and hence to more homogeneity, rather than diversity.

If we wish to maintain and even increase the diversity of higher education systems, we will have to develop different ranking instruments in which different forms of institutional performance can be compared. We should design multiple ranking instruments that enable us to make inter-institutional comparisons per category or type of institution. In order to create higher levels of diversity in higher education systems, we therefore need to develop typologies of higher education institutions. In these typologies (or classifications) the diversity of institutional missions and profiles should be made transparent, offering the different stakeholders a better understanding of the specific ambitions and performances of the various types of higher education institutions (see Bartelse and van Vught, 2007).

The emergence of the discussions on rankings and typologies shows that diversity and differentiation are concepts that appear to remain relevant in the future contexts of both higher education policy making and institutional management. A better understanding of these concepts and more systematic and empirical investigations will be crucial in order to allow us to design effective policies and successful institutional management strategies in higher education.

\section{References}

Aldrich, H.E. (1979) Organizations and Environments, Englewood Cliffs: Prentice-Hall.

Bartelse, J. and van Vught, F. (2007) 'Institutional profiles: toward a typology of higher education institutions in Europe', IAU Horizons 13(2-3): 9-11.

Birnbaum, R. (1983) Maintaining Diversity in Higher Education, San Francisco: Jossey-Bass.

Bowen, H. (1980) The Cost of Higher Education, San Francisco: Jossey-Bass.

Brewer, D.J., Gates, S.M. and Goldman, C.A. (2002) In Pursuit of Prestige: Strategy and Competition in US Higher Education, New Brunswick: Transaction Press.

Carnegie Commission on Higher Education. (1973) The Purposes and the Performance of Higher Education in the United States, New York: McGraw-Hill.

Clark, B.R. (1978) 'United States', in J.H. van de Graaff, B.R. Clark, D. Furth, D. Goldschmidt and D. Wheeler (eds.) Academic Power: Patterns of Authority in Seven National Systems, New York: Praeger. 
Clark, B.R. (1983) The Higher Education System, Berkeley and Los Angeles: University of California Press.

Coleman, J.S. (1990) Foundation of Social Theory, Cambridge: Harvard University Press.

Dill, D.D. (2003) 'Allowing the market to rule: the case of the United States', Higher Education Quarterly 57(2): 136-157.

DiMaggio, P.J. and Powell, W.W. (1983) 'The iron cage revisited: institutional isomorphism and collective rationality in organizational fields', American Sociological Review 48: 147-160.

Durkheim, E. (1964 1893) The Division of Labor in Society, New York: The Free Press.

Fox, W. (1993) 'Higher education policy in California', in L. Goedegebuure, F. Kaiser, P. Maassen, L. Meek, F. van Vught and E. de Weert (eds.) Higher Education Policy: An International Comparative Perspective, Oxford: Pergamon Press, pp. 49-82.

Friedman, B.M. (2002) 'Globalization: Stiglitz's case', (Review of Joseph E. Stiglitz, Globalization and its discontents), New York Review, 15 August 2002.

Garvin, D.A. (1980) The Economics of University Behavior, New York: Academic Press.

Geiger, R.L. (2004) Knowledge and Money, Research Universities and the Paradox of the Marketplace, Stanford: Stanford University Press.

Hannan, M.T. and Freeman, J. (1977) 'The population ecology of organizations', American Journal of Sociology 82: 929-964.

Hannan, M.T. and Freeman, J. (1989) Organizational Ecology, Cambridge: Harvard University Press.

Hawley, A.H. (1986) Human Ecology; A Theoretical Essay, Chicago: University of Chicago Press.

Huisman, J. (1995) Differentiation, Diversity and Dependency in Higher Education, Utrecht: Lemma.

Huisman, J., Meek, L. and Wood, F. (2007) 'Institutional diversity in higher education: a crossnational and longitudinal analysis', Higher Education Quarterly 61(4): 563-577.

Maassen, P.A.M. and Potman, H.P. (1990) 'Strategic decision making in higher education, an analysis of the new planning system in Dutch higher education', Higher Education 20: 393-410.

Massy, W.F. (2003) Honoring the Trust, Quality and Cost Containment in Higher Education, Boston: Anker.

Meek, V.L. (1991) 'The transformation of Australian higher education: from binary to unitary system', Higher Education 21: 461-494.

Meek, V.L. (2003) 'Governance and management of Australian higher education: enemies within and without', in A. Amaral, V.L. Meek and I.M. Larsen (eds.) The Higher Education Management Revolution?, Dordrecht: Kluwer, pp. 235-260.

Merton, R. (1968) Social Theory and Social Structure, New York: The Free Press.

Morgan, G. (1986) Images of Organization, London: Sage.

Morphew, C.C. (2006) 'Conceptualizing change in the institutional diversity of US colleges and universities', Mimeo, Institute of Higher Education, University of Georgia.

Neave, G. (1979) 'Academic drift: some views from Europe', Studies in Higher Education 4(2): 143159.

Newman, F., Couturier, L. and Scurry, J. (2004) The Future of Higher Education, Rhetoric, Reality and the Risks of the Marketplace, San Francisco: Jossey-Bass.

Parsons, T. (1966) Societies: Evolutionary and Comparative Perspectives, Englewood Cliffs: Prentice-Hall.

Parsons, T. and Platt, G.M. (1973) The American University, Cambridge: Harvard University Press. Pfeffer, J. and Salancik, G.R. (1978) The External Control of Organizations, A Resource Dependence Perspective, New York: Harper and Row.

Rhoades, G. (1983) 'Conflicting interests in higher education', American Journal of Education 91: 283-327. 
Lif. Frans van Vught

Th Mission Diversity and Reputation in Higher Education

174

Rhoades, G. (1990) 'Political competition and differentiation in higher education', in J.C. Alexander and P. Colony (eds.) Differentiation Theory and Social Change, New York: Columbia University Press, pp. 187-221.

Riesman, D. (1956) Constraint and Variety in American Education, Lincoln: University of Nebraska Press.

Skolnik, M.L. (1986) 'Diversity in higher education: the Canadian case', Higher Education in Europe 11: 19-32.

Smelser, N. (1959) Social Change in the Industrial Revolution, Chicago: University of Chicago Press. Trow, M. (1979) Elite and Mass Higher Education: American Models and European Realities, Stockholm: National Board of Universities.

van Vught, F. (1992) Governmental Strategies and Innovation in Higher Education, London: Jessica Kingsley. 